\title{
Heart mitochondrial dysfunction in diabetic rats
}

\author{
Silvina S. BOMbICINO*, Darío E. IGLESIAS, Ivana A. RUKAVINA MIKUSIC, Alberto BOVERIS \\ AND LAURA B. VALDEZ
}

Key words: Diabetes, Diabetic cardiomyopathy, heart, mitochondria, nitric oxide

\begin{abstract}
Diabetic cardiomyopathy, i.e. the ventricular dysfunction in the absence of hypertension or coronary arterial disease, is a common complication of diabetes mellitus that leads to a heightened risk of heart failure and death among diabetic patients. This contractile dysfunction could be associated to mitochondrial dysfunction, in which mitochondrial biogenesis could emerge as a compensatory mechanism triggered in response to hyperglycemia. It has been proposed that nitric oxide synthase activities with enhanced NO production are involved in this process. Alterations in the contractile response and lusitropic reserve were observed in streptozotocin diabetic rats after $\beta$-adrenergic stimuli. Additionally, tissue $\mathrm{O}_{2}$ consumption was declined. A condition of mitochondrial dysfunction with decreased mitochondrial state $3 \mathrm{O}_{2}$ consumption, respiratory control ratio, mitochondrial respiratory complexes activities and ATP production were present in hearts of diabetic animals. We observed an increase in NO production by heart mitochondria and in cytochrome oxidase activity in heart homogenates. The latter suggests an increase of newly formed mitochondria. Thus, the impairment of mitochondrial function with increased mitochondrial biogenesis may precede the onset of diabetic cardiomyopathy. However, mitochondrial biogenesis does not necessarily imply that the resultant mitochondria are functional, which might explain the changes in cardiac energy metabolism occurring in hearts of diabetic rats.
\end{abstract}

Diabetes mellitus is a chronic metabolic disease characterized by increased blood glucose levels (hyperglycemia), which may result from defective insulin secretion by pancreatic $\beta$ cells, impaired insulin action in target tissues or both. Hyperglycemia itself is a risk factor for diabetic patients, associated with long-term damage, dysfunction, and failure of various organs, especially the eyes, kidneys, nerves, heart and blood vessels (American Diabetes Association, 2008).

Diabetes is a well-recognized risk factor for developing heart failure (Boudina and Dale Abel, 2007). Chronic diabetes is associated with a primary cardiomyopathy as indicated by cardiac contractile dysfunction, coupled with low ATP levels. This ventricular dysfunction, in the absence of hypertension or coronary arterial disease, is known as "diabetic cardiomyopathy" (Hambly et al. 1974), a common

\footnotetext{
*Address correspondence to: Silvina S. Bombicino sbombicino@ffyb.uba.ar

Received: October 30, 2015. Accepted: April 16, 2016
}

complication of diabetes which leads to heightened risk of heart failure and death (Fein, 1990; Bell, 2003). Diabetic cardiomyopathy is characterized by biochemical, mechanical, structural and electrical changes in the heart, occurring before the appearance of diastolic dysfunction (Pacher and Szabó, 2006). The pathogenesis of diabetic cardiomyopathy is still not well characterized; however, This part of the sentence should be deleted and replaced by: increasing number of evidences suggest that mitochondrial dysfunction and abnormalities in mitochondrial energetics in cardiomyocytes contribute to the development of cardiac dysfunction in diabetic patients (Pierce and Dhalla, 1985; Ferreira et al., 2003). The heart is a highly $\mathrm{O}_{2}$-dependent organ. Normal cardiac function is accomplished through a continuous energy supply provided by mitochondria, which produce 95\% of total cellular ATP by oxidative phosphorylation (Neubauer, 2007). In addition, the heart needs to maintain a redox balance to develop the contraction force. In diabetic patients, the heart is continuously exposed to high glucose 
and fatty acids concentrations, which generate an oxidative environment. A redox imbalance with an increment of heart mitochondrial reactive oxygen species production and mitochondrial uncoupling was observed in diabetic patients, leading to an impairment of myocardial energetics (Boudina, 2007; Aon et al., 2015). Moreover, it has been shown that the activities of enzymes which generate reactive species, such as xanthine oxidase (Rajesh et al., 2009) and NADPH oxidase (Varga et al., 2015) are increased in the diabetic heart. The changes in energy metabolism, the increase in substrates supply and the augmented mitochondrial production of reactive oxygen species (especially superoxide anion, $\mathrm{O}_{2}^{-}$), could be implicated in diabetic complications. The modifications in the mitochondrial redox status influence on the energetic balance of cardiomyocytes, altering mechanical and electrical functions of the heart (excitation-contraction coupling) (Christians and Benjamin, 2012).

It has been reported (Stockklause-Farber et al. 2000; Rajesh et al. 2012) that diabetes causes a higher expression of cardiac nitric oxide synthases (eNOS and iNOS). These enzymes are responsible of producing nitric oxide (NO) in the heart, being essential for heart homeostasis and mechanical activity (Valdez et al., 2011). The enhancement in NO production could be associated with nitration of cytoskeletal proteins, leading to alterations in cardiac contractility (Khanna et al., 2014). In diabetic hearts, the inhibition of NOS activity by L-NMMA or L-NAME, improves cardiac activity, suggesting that both $\mathrm{NO}$ and peroxynitrite $\left(\mathrm{ONOO}^{-}\right)$could be associated with the inhibition of cardiac contractility (Smith et al., 1997). In addition, mitochondria produce $\mathrm{NO}$ in a reaction catalyzed by mitochondrial nitric oxide synthase (mtNOS) (Giulivi et al., 1998; Zaobornyj and Ghafourifar, 2012). Mitochondrial NO production accounts for about $60 \%$ of total heart NO generation (Zaobornyj et al., 2009) and it is produced at a rate of 1.0-1.4 nmol NO. $\mathrm{min}^{-1} . \mathrm{mg}$ protein $^{-1}$ (Valdez et al., 2006; Valdez et al., 2007). Experimental and clinical evidences suggest that nitrosative stress could be part of the pathogenesis of diabetic cardiomyopathy. Pacher and Szabó (2006) have shown a correlation between the severity of the diastolic dysfunction and the content of protein tyrosine nitration in myocytes, fibroblasts and endothelial cells, both in diabetic patients and in streptozotocin diabetic rats.

Thus, the increased production of free radicals and/or the impairment of antioxidants defense capabilities show the central contribution of reactive oxygen and nitrogen species in the onset, progression and pathological consequences of diabetes (Chen et al., 1998). The enhancement in reactive oxygen species produced by mitochondria might contribute with mitochondrial uncoupling, which could impair myocardial energetics in diabetes (Boudina, 2007). Cardiac failure could be associated with impairment in energy metabolism, mainly caused by mitochondrial dysfunction, with diminished ATP production (Rolo and Palemira, 2006).
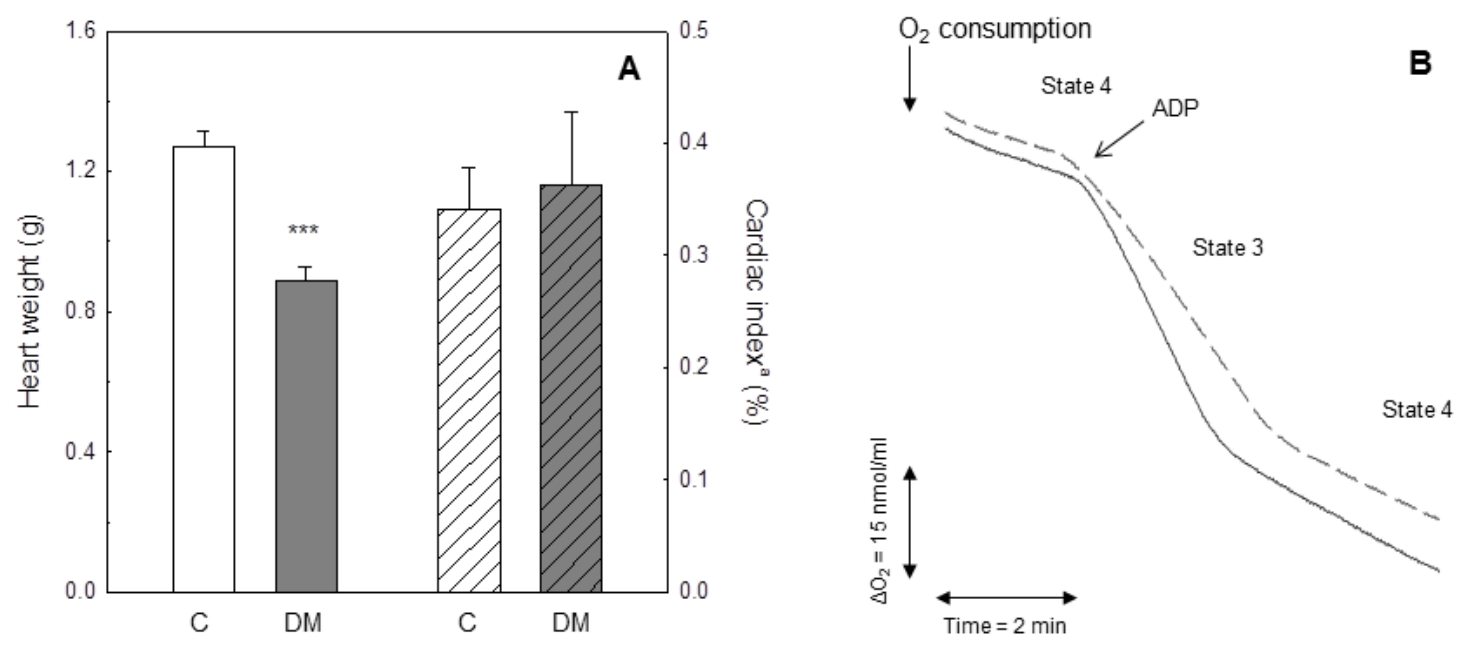

FIGURE 1. A. Heart weight (full bars) and cardiac index (striped bars) 4 weeks after streptozotocin treatment . ${ }^{\circ} \mathrm{C}-$ ardiac index (\%) was calculated as the ratio between heart weight and animal weight. C = Control group /white bars), $\mathrm{DM}=$ Diabetic group (grey bars). ${ }^{* *} \mathrm{p}<0.005$ vs. control animals. B. Representative traces showing This Word should be replaced by heart mitochondrial $\mathrm{O}_{2}$ consumption using malate-glutamate as substrates, in control (full line) and diabetic (dotted line) animals. 
Results of our laboratory showed that after 4 weeks of streptozotocin injection (i.p. $60 \mathrm{mg} / \mathrm{kg}$ animal weight) to male rats, cardiac ventricular dysfunction occurs. Although no differences were detected under basal conditions, both the contractile response (40\%) and the lusitropic reserve (55\%) were lower after $\beta$-adrenergic stimuli in diabetic than in control animals. However, no cardiac hypertrophy, evidenced through a similar cardiac index, was present (Fig. 1A). Tissue $\mathrm{O}_{2}$ consumption was slightly lower (15\%) in diabetic hearts, which was attributable to an impairment in the mitochondrial respiratory chain, because the observed difference in heart $\mathrm{O}_{2}$ uptake depends on the fraction sensitive to KCN inhibition. Thereby, heart mitochondrial function was impaired in diabetic animals as indicated by a lower $\mathrm{O}_{2}$ uptake when malate-glutamate was used as substrate $(22 \%)$, with a concomitant decrease in respiratory control and ADP/O ratios (Fig. 1B). Moreover, the activities of the mitochondrial respiratory complexes (I-III, 22\%; II-III, 30\% and IV, 22\%) and the rate of ATP production were significantly lower (40\%) in diabetic than in control rats. These results indicate that the impairment of the mitochondrial function and of the coupling and efficiency of oxidative phosphorylation may precede the onset of diabetic cardiomyopathy.

Mitochondrial biogenesis may act as a compensatory mechanism of mitochondrial dysfunction triggered by hyperglycemia. It has been shown that there is an association between mtNOS expression and/or activity in the mitochondrial biogenesis process, in which $\mathrm{NO}$ is involved (Navarro et al., 2005). Accordingly, an increase in mitochondrial NO production $(23 \%)$ was observed in hearts of streptozotocin induced-diabetic rats. Moreover, cytochrome oxidase activity measured in heart homogenates, indicates that the mitochondrial mass per tissue mass was $45 \%$ higher in diabetic animals (as compared with controls), suggesting that diabetes leads to mitochondrial biogenesis. However, this does not necessarily imply that the newly formed mitochondria are functional (Vanasco et al., 2014) and so, cardiac energy metabolism may still be impaired.

As a conclusion, diabetes leads to a heart mitochondrial dysfunction with increased mitochondrial biogenesis, in which NO may be involved. This process could be triggered in response to hyperglycemia and may explain the impairment in cardiac energy metabolism that occurs in the heart of diabetic rats.

\section{Acknowledgement}

This work was supported by research grants from the University of Buenos Aires (UBACYT 200-201-101-00140 and 200-201-301-00731), Agencia Nacional de Promoción
Científica y Tecnológica (PICT 2012-0964), and Consejo Nacional de Investigaciones Científicas y Técnicas (PIP 112-201-101-00444).

\section{References}

American Diabetes Association (2008). Diagnosis and Classification of Diabetes Mellitus. Diabetes Care 31: 555-560.

Aon MA, Tocchetti CG, Bhatt N, Paolocci N, Cortassa S, (2015). Protective Mechanisms of Mitochondria and Heart Function in Diabetes. Antioxidants and Redox Signaling 22: 1563-1586.

Bell DS. (2003) Diabetic cardiomyopathy. Diabetes Care 26: 2949-2951.

Boudina S, Dale Abel E (2007). Diabetic cardiomyopathy Revisited. Circulation 115: 3213- 3223.

Chen Z, Siu B, Ho YS, Vincent R, Chua CC, Hamdy RC, Chua BH (1998). Overexpression of MnSOD protects against myocardial ischemia/ reperfusion injury in transgenic mice. Journal of Molecular Cell Cardiology 30: 2281-2289.

Christians ES, Benjamin IJ (2012). Proteostasis and REDOX state in the heart. American journal of physiology. Heart and circulatory physiology 302: $\mathrm{H} 24-\mathrm{H} 37$.

Fein FS. (1990) Diabetic cardiomyopathy. Diabetes Care 13: 1169-1179.

Ferreira FM, Palmeira CM, Seica R, Moreno AJ, Santos MS (2003). Diabetes and mitochondrial bioenergetics: alterations with age. Journal of biochemical toxicology 17: 214-222.

Giulivi C, Poderoso JJ, Boveris A (1998). Production of nitric oxide by mitochondria, Journal of Biological Chemistry 273: 11038-11043.

Hambly RI, Zoneraich S, Sherman L (1974). Diabetic Cardiomyopathy. Journal of the American Medical Association 229:1749-1754.

Khanna S, Bir Singh G, Khullar M (2014). NOS and diabetic cardiomyopathy. Nitric Oxide 43: 29-34

Navarro A, Torrejon R, Bandez MJ, Lopez-Cepero JM, Boveris A (2005). Mitochondrial function and mitochondria-induced apoptosis in an overstimulated rat ovarian cycle, American journal of physiology. Endocrinology and metabolism 289: E1101-1109.

Neubauer S (2007). The failing heart - an engine out of fuel. New England Journal of Medicine 365: 1140-1151.

Pacher P, Szabó C (2006). Role of peroxinitrite in the pathogenesis of cardiovascular complications of diabetes. Current Opinion in Pharmacology 6: 136-141

Pierce GN, Dhalla NS (1985). Heart mitochondrial function in chronic experimental diabetes in rats. The Canadian Journal of Cardiology 1: $48-54$.

Rajesh M, Mukhopadhyay P, Bátkai S, Mukhopadhyay B, Patel V, Haskó G, Szabó C, Mabley JG, Liaudet L, Pacher P. (2009). XO inhibitor allopurinol attenuates the development of diabetic cardiomyopathy. Journal of medicine and biochemistry 13: 2330-2341

Rajesh M, Bátkai S, Kechrid M, Mukhopadhyay P, Lee WS, Horváth B, Holovac E, Cinar R, Liaudet L, Mackie K, Haskó G and Pacher P (2012). Cannabinoid 1 receptor promotes cardiac dysfunction, oxidative stress, inflamation, and fibrosis in diabetic cardiomyopathy. Diabetes 61: 716-727.

Rolo A, Palemira C, (2006). Diabetes and mitochondrial function: Role of hyperglycemia and ox stress. Toxicology and Applied pharmacology 212: 167-178.

Smith JM, Paulson DJ, Romano FD (1997). Inhibition of Nitric Oxide Synthase by L.NAME improves ventricular performance in STZ-diabetic rats. Journal of molecular and cellular cardiology 29: 2393-2404

Stockklauser-Färber K, Ballhausen T, Laufer A, Rösen P (2000). Influence of diabetes on cardiac nitric oxide synthase expression and activity. Biochimica et Biophysica Acta 1535: 10-20. 
Valdez LB, Zaobornyj T, Boveris A (2006). Mitochondrial metabolic states and membrane potential modulate mtNOS activity. Biochimemical et Biophysical Acta 1757: 166-172.

Valdez LB, Boveris A (2007). Mitochondrial nitric oxide synthase, a voltage-dependent enzyme, is responsible for nitric oxide diffusion to cytosol, Frontiers in Bioscience 12: 1210-1219.

Valdez LB, Zaobornyj T, Bombicino S, Iglesias DE, Boveris A, Donato M, D'Annunzio V, Bucholz B, Gelpi RJ (2011). Complex I syndrome in myocardial stunning and the effect of adenosine. Free Radical Biology and Medicine 51: 1203-1212.

Vanasco V, Saez T, Magnani ND, Pereyra L, Marchini T, Corach A, Vaccaro MI, Corach D, Evelson P, Alvarez S. (2014). Cardiac mitochondrial biogenesis in endotoxemia is not accompanied by mitochondrial function recovery. Free Radical Biology and Medicine 77: 1-9.
Varga ZV, Giricz Z, Liaudet L, Haskó G, Ferdinandy P, PacherP (2015). Interplay of oxidative, nitrosative/nitrative stress, inflammation, cell death and autophagy in diabetic cardiomyopathy. Biochimica et biophysica acta 1852:232-42.

Zaobornyj T, Valdez LB, Iglesias DE, Gasco M, Gonzales GF, Boveris A (2009). Mitochondrial nitric oxide metabolism during rat heart adaptation to high altitude: effect of sildenafil, L-NAME, and L-arginine treatments. American journal of physiology. Heart and circulatory physiology 296: H1741-7.

Zaobornyj T, Ghafourifar P (2012). Strategic localization of heart mitochondrial NOS: a review of the evidence. American Journal of Physiology - Heart Circulatory Physiology 303: 1283-1293. 